\title{
Levels of a subpopulation of platelets, but not circulating endothelial cells, predict early treatment failure in prostate cancer patients after prostatectomy
}

\author{
CKE Wong ',4, B Namdarian 2,4 ${ }^{2}$ J Chua', X Chin', R Speirs', T Nguyen², M Fankhauser², J Pedersen ${ }^{3}$, \\ AJ Costello ${ }^{1,2}$, NM Corcoran ${ }^{1,2}$ and CM Hovens ${ }^{*, 1,2}$ \\ 'Australian Prostate Cancer Research Centre at Epworth Hospital, Richmond, Victoria, Australia; ${ }^{2}$ Department of Surgery, University of Melbourne, \\ Royal Melbourne Hospital, Parkville, Victoria 3050, Australia; ${ }^{3}$ TissuPath Pty Ltd, Glen Waverly, Victoria, Australia
}

BACKGROUND: Angiogenesis is one of the hallmarks of cancer driving tumour growth and ultimately metastasis. Circulating endothelial cells (CECs) and circulating endothelial progenitor (CEPs) cells have been reported as candidate surrogate markers for tumour vascularisation. Our aim was to investigate the potential use of these circulating cells levels as predictors of prostate cancer treatment failure and metastasis.

METHODS: We examined the levels of $\mathrm{CD} 3 \mathrm{I}^{+} \mathrm{CD} 5^{-}$cells (CECs) and CD31 ${ }^{+} \mathrm{CD} 45^{-} \mathrm{CD} 117^{+}$(CEPs) in s.C. and orthotopic models of human prostate cancers and correlated measurements with tumour size, volume and microvessel density (MVD). We then performed a prospective cohort study in 164 men with localised prostate cancer undergoing prostatectomy. The CD31 ${ }^{+} \mathrm{CD} 45^{-}$, $\mathrm{CD} 31^{+} \mathrm{CD}_{4} 5^{-} \mathrm{CDI} 46^{+}$(CECs) and $\mathrm{CD} 31^{+} \mathrm{CD} 45^{\text {intermediate }} \mathrm{CDI} 33^{+}$(CEPs) populations were quantified and subsequently enriched for further characterisation.

RESULTS: In preclinical models, levels of CD31 ${ }^{+} \mathrm{CD} 45^{-}$cells, but not CEPs, were significantly elevated in tumour-bearing mice and correlated with tumour size, volume and MVD. In our human prospective cohort study, the levels of CD31 ${ }^{+} \mathrm{CD} 45^{-}$cells were significantly higher in men who experienced treatment failure within the first year, and on logistic regression analysis were an independent predictor of treatment failure, whereas neither levels of CECs or CEPs had any prognostic utility. Characterisation of the isolated $\mathrm{CD} 3 \mathrm{I}^{+} \mathrm{CD}_{4}{ }^{-}$cell population revealed an essentially homogenous population of large, immature platelets representing $<0.1 \%$ of circulating platelets.

CONCLUSION: Elevated levels of a distinct subpopulation of circulating platelets were an independent predictor for early biochemical recurrence in prostate cancer patients within the first year from prostatectomy.

British Journal of Cancer (20 I2) I 07, I564-1573. doi:I0.I038/bjc.20 I2.439 www.bjcancer.com

Published online 9 October 2012

(C) 2012 Cancer Research UK

Keywords: platelets; CECs; CEPs; prostate cancer

Prostate cancer is the most commonly diagnosed internal malignancy and the second leading cause of cancer death among men in the Western world. When considered against the fact that only males can develop the disease, the prostate is by far the most cancer susceptible internal organ within the body. In spite of the great propensity of the prostate gland to undergo malignant transformation, the majority of these tumours are clinically indolent and represent no threat to life, while a smaller but still significant number of cancers are lethal.

The decision to treat or observe a newly diagnosed, clinically localised prostate cancer is determined largely by the anticipated natural history of the disease in the absence of therapy. Although there are a number of different predictive tools for use in the clinical setting, based primarily on serum PSA, digital rectal examination, and the histopathological examination of diagnostic

\footnotetext{
*Correspondence: Dr CM Hovens; E-mail: chovens@unimelb.edu.au

${ }^{4}$ These authors contributed equally to this work.

Received 19 June 2012; revised 28 August 2012; accepted 30 August 2012; published online 9 October 2012
}

cores, due to both the well documented sampling error in the biopsy process as well as inherent biological variability within tumours of similar pathology, current methods fail to reliably discriminate indolent tumours from those with metastatic potential (Corcoran et al, 2011, 2012). There is thus a real clinical need for new biomarkers that allow for the early detection of highrisk prostate cancer, which would assist in risk stratification and prognostication of prostate cancer patients.

Angiogenesis is one of the hallmarks of cancer driving tumour growth and ultimately metastasis. At present, tissue microvessel density (MVD) is the main parameter used to evaluate tumour angiogenesis. However, this approach has its limitations including the need for an invasive procedure for tissue procurement, the inaccuracy of MVD measurement in limited tumour biopsies compared with whole tumour specimens, and more importantly the lack of correlation with clinical outcomes (Nico et al, 2008). Recently, surrogate markers for tumour vascularisation, in particular circulating endothelial cells (CEC) and circulating endothelial progenitor (CEP) cells, have emerged as potentially useful biomarkers for various cancers including renal cell carcinoma, gastrointestinal cancer, breast cancer and lymphoma 
(Mancuso and Bertolini, 2010). A panel of cell surface markers are commonly used in flow cytometry to identify CECs and CEPs in peripheral blood samples (Blann et al, 2005; Mancuso et al, 2009). Circulating endothelial cells are phenotypically identified based on the expression of endothelial markers (including CD31 and CD146) together with the absence of expression of leukocyte marker (CD45) and immaturity marker (CD133). Activated CECs have positive expression of CD105 and CD106. Circulating endothelial progenitors are identified by the expression of CD133.

Circulating endothelial cells, a subpopulation of endothelial cells, are thought to be shed from established blood vessels into the circulation following detachment from the basement membrane during angiogenesis, whereas CEPs originate from the bone marrow and have a role in neovascularisation (Mancuso and Bertolini, 2010). Preclinically in different tumour models, levels of CECs and CEPs have been shown to correlate with disease states and treatment outcomes (Monestiroli et al, 2001; Shaked et al, 2005a, b; Mancuso et al, 2006). It has been shown that mean CEC levels were elevated 3.3-fold in cancer patients compared with healthy controls and that patients with progressive disease had higher CEC levels, whereas patients with stable disease had similar CEC levels to healthy volunteers (Beerepoot et al, 2004). In addition, lymphoma patients with complete remission (Monestiroli et al, 2001) and breast cancer patients receiving metronomic treatments (chemotherapy and oral drugs) (Dellapasqua et al, 2008; Calleri et al, 2009) and postmastectomy patients (Mancuso et al, 2001) presented with CEC levels that were comparable to healthy controls; lower CEC levels were also associated with prolonged survival outcome in gastrointestinal cancer patients treated with an antiangiogenic agent (NordenZfoni et al, 2007). There is conflicting evidence surrounding the contribution of CEPs to (a) tumour vascularisation and (b) as biomarkers for prognostication and treatment response. Although it has been shown that CEPs contribute to tumour vascularisation in several malignancies (Lyden et al, 2001; Reyes et al, 2002; Dwenger et al, 2004; Peters et al, 2005), two studies (De Palma et al, 2003; Gothert et al, 2004) have suggested that CEPs make minimal contributions to tumour vasculature. Similarly, although CEPs have been reported as a potential biomarker for treatment responses (Dome et al, 2006; Calleri et al, 2009; Goon et al, 2009), several studies have reported no correlation between CEP levels and disease outcomes (Mancuso et al, 2001, 2006; Ronzoni et al, 2010). Clearly, the prognostic value of CEPs requires further validation.

Although there is a strong case for CECs as biomarkers for tumour progression and treatment efficacy in other tumour types, it is unclear whether CECs have prognostic utility in prostate cancer to predict treatment response in patients with localised prostate cancer treated surgically. In this study, we investigated the predictive potential of circulating cells, including CECs and CEPs, as biomarkers for early treatment failure in patients with localised prostate cancer.

\section{MATERIALS AND METHODS}

\section{Cell lines and culture conditions}

All cell lines were purchased from American Type Culture Centre (ATCC, Sydney, NSW, Australia). PC3 (Cat No: CRL-1435) and MDA-MB-231 (Cat No: HTB-26) cell lines were cultured in RPMI media (Invitrogen, Carlsbad, CA, USA) with added 10\% fetal bovine serum (FBS) and $1 \%$ penicillin/streptomycin. Lewis lung carcinoma (LLC) (Cat No: CR-1642) cells were cultured in DMEM media (Invitrogen) with 10\% FBS and 1\% penicillin/streptomycin. LNCaP (Cat No: CRL-1740) and AI-LNCaP (a subline of CRL-1740) cell lines were cultured in RPMI media with added $10 \%$ FBS, $4.5 \mathrm{gl}^{-1} \mathrm{D}$-glucose, $1 \mathrm{~mm}$ sodium pyruvate, $10 \mathrm{~mm}$ HEPES and $1 \%$ penicillin/streptomycin. AI-LNCaP cells were developed as follows: LNCAP-FGC cells (Soto et al, 1995) passage 23 were seeded at 70$80 \%$ confluency, washed twice in $1 \times \mathrm{PBS}$, serum starved for $48 \mathrm{~h}$ then placed in RPMI 1641 media supplemented with 5\% Charcoalstripped serum (CSS; Hyclone, Logan, UT, USA, \#SH30068.93). Widespread apoptotic cell death ensued after 5-7 days leaving approximately $10-20 \%$ of cells intact, characterised by prominent neuroendocrine differentiation. This process was repeated a further five times until a cell line was selected, AI-LNCaP that proliferates with almost identical kinetics in 5\% CSS media or $10 \%$ FCS media. All cells were cultured in T175 flasks and incubated at $37^{\circ} \mathrm{C}, 5$ or $10 \% \mathrm{CO}_{2}$. The expanded cell populations were detached from flasks using $1 \times$ Trypsin/EDTA solution, in preparation for either passaging or xenograft injection.

\section{Xenografting}

Four-to eight-week-old severe combined immune deficiency (SCID) mice were injected with $1 \times 10^{7}$ cancer cells. A minimum of six mice were used for each cancer cell line and all mice were anaesthetised before the subsequent procedure. For s.c. models, AI-LNCaP and LLC cells were injected at a single site with an equal volume of BD Matrigel matrix (BD Biosciences, North Ryde, NSW, Australia, Cat No: 356237). For orthotopic models, MDA-MB-231 cells were injected into mammary fat pads and PC3, LNCaP and AI-LNCaP cells were injected into the dorsolateral lobe of the prostate without matrigel.

\section{Blood collection (mouse)}

Up to $200 \mu$ l of blood was collected from each mouse weekly via mandibular bleed. Blood was transferred into Microtainer Collection Tube (BD Biosciences, Cat No: 367839) containing either $\mathrm{K}_{2}$ EDTA or lithium heparin (BD Biosciences, Cat No: 365985) anticoagulant and placed immediately on ice. At the end of experiment, mice were euthanised and a cardiac puncture was performed to obtain a large, end-point volume of blood from each mouse.

\section{Tumour monitoring and collection}

Subcutaneous tumour growth was measured weekly using callipers. Dimensions were taken along the length and perpendicular width, with length the greatest dimension of the tumour at each assessment. Tumour volume was calculated using the following formula: Tumour volume $\left(\mathrm{mm}^{3}\right)=0.52 \times A \times B^{2}$, where $A=$ longer dimension and $B=$ shorter dimension. At the end of experiment, s.c. tumours were dissected from the abdominal wall and overlying skin, and excised discretely. Mammary fat pads tumours were retrieved in a similar fashion to s.c. tumours. In the intraprostatic models, the intact tumour-containing glands were removed. Following excision, all tumours were weighed and measured.

\section{Assessment of MVD}

The MVD was assessed as a histological measure of intratumoural vascularity in orthotopic models. Tumour tissues were sectioned $(5 \mu \mathrm{m})$ and placed on Histobond (Leica, Marienfeld, Germany) silanized glass slides. Rehydration was performed through three immersions into xylene and then gradient ethanol immersion. Endogenous peroxidase activity was blocked by immersion in $0.3 \%$ hydrogen peroxide in $\mathrm{PBS}$ for $5 \mathrm{~min}$ at room temperature. Following washes in PBS, tissues were incubated with purified rat anti-mouse CD31 antibody (BD Pharmingen, North Ryde, NSW, Australia) diluted $1: 75$ in $0.5 \%$ BSA in PBS, at room temperature for $2 \mathrm{~h}$ in a humidified chamber. Following washes, tissues were incubated with a 1:75 dilution of horseradish 
peroxidase-conjugated goat anti-rat Ig-specific polyclonal antibody (Dako, Botany, NSW, Australia) in PBS for $30 \mathrm{~min}$ at room temperature. Peroxidase signal was developed using 3,3'-diaminobenzidine liquid substrate system (Sigma-Aldrich, St Louis, MO, USA). Sections were washed and counterstained with haematoxylin before dehydration and coverslipping with DPX resin (BDH Labs). Single, brown staining endothelial cells or clusters of contiguous endothelial cells were considered to represent a single microvessel in this study. Three areas of highest staining were examined and the number of microvessels was scored by two independent investigators. Average counts were used for subsequent correlation analysis.

\section{Human study}

After informed consent, blood was taken from the arterial line once the patient was anaesthetised but before the commencement of prostatectomy, with the initial $5 \mathrm{ml}$ being discarded before sample aspiration. Initially, $\mathrm{K}_{2}$ EDTA Vacutainer Collection Tubes (Becton Dickinson, North Ryde, NSW, Australia) were used for blood collection for the first half of the presurgery group, and samples were processed within $90 \mathrm{~min}$ of blood collection. Subsequently, CellSave preservative tubes (Veridex, Johnson and Johnson, North Raritan, NJ, USA) were used for blood collection and samples were processed within $96 \mathrm{~h}$ of blood collection.

Preoperative blood was collected for CEC and CEP analysis on the day of surgery in 164 men with localised prostate cancer. The CEC and CEP levels were analysed for correlation with known clinical and pathological characteristics of prostate cancer. In addition, to demonstrate that a specific subpopulation of platelets, but not total platelets, are an independent predictor of treatment failure, the levels of total platelets before surgery were analysed retrospectively in a larger independent cohort of 364 prostatectomy patients.

\section{Blood preparation for flow cytometry analysis}

Both murine and human blood samples were similarly processed according to previously published protocol for flow cytometry analysis (Duda et al, 2006). Briefly, whole blood was centrifuged and plasma was removed. Samples were washed twice in wash buffer $(1 \times$ PBS with $0.5 \%$ BSA, 1.5 mm EDTA $)$ and resuspended in $500 \mu \mathrm{l}$ wash buffer. Mouse blood samples were incubated with mouse FcR blocking reagent (Miltenyi, North Ryde, NSW, Australia, Cat No: 120-003-855). Next, samples were incubated with anti-mouse rat antibodies, namely, CD31-FITC (BD Biosciences, Cat No: 558738), CD45-PerCP (BD Biosciences, Cat No: 557235) and CD117-PE (BD Biosciences, Cat No: 553355). After incubation samples were resuspended in ACK Red Cell Lysing Buffer (Invitrogen, Cat No. A10492), washed twice and passed through a $35 \mu \mathrm{m}$ cell strainer (BD Biosciences, Cat No: 352235 ). Human blood samples were processed in a similar manner, human FCR blocking reagent (Miltenyi, Cat No: 120-000-442) and antihuman mouse antibodies, namely, CD31-FITC (BD Biosciences, Cat No: 555445) CD45-PerCP (BD Biosciences, Cat No: 347464), CD133-APC (Miltenyi, Cat No: 130-090-826) and CD146-PE (BD Biosciences, Cat No: 550315) were substituted. In addition, mouse anti-human CD41a (BD Biosciences, Cat No: 559777) and CD42b (BD Biosciences, Cat No: 551061) antibodies were used as plateletspecific markers (Breton-Gorius and Vainchenker, 1986; Koike et al, 1987; Tomer et al, 1988; Vainchenker and Kieffer, 1988; Demirer et al, 2001; Drayer et al, 2006; Schneider and TaatjesSommer, 2009). Fifty microlitre of FlowCount fluorosphere suspension (Beckman Coulter, Brea, CA, USA, Cat No: 7547053) was added to each samples and placed on ice until flow cytometry analysis. The concentration of any cell population was calculated using the formula: Concentration of cell $\mathrm{A}=$ number of cell $\mathrm{A}$ (event count) $\times$ concentration of beads $\times$ volume of beads/ (number of beads $\times$ volume of blood).

For both murine and human CECs analysis, flow cytometry plots were analysed using either Win MDI version 2.9 (J. Trotter, Scripps Institute, CA, USA) or FACS Diva software (BD Biosciences). Forward and side scatters plot was used to determine the region containing mononuclear cells while excluding small platelets, cell debris and granulocytes (Supplementary Figure 1). In both the mouse and human samples CEC enriched populations were defined as $\mathrm{CD} 31^{+} \mathrm{CD} 45^{-}$. For mouse experiments, the CEP population was defined as $\mathrm{CD} 31^{+} \mathrm{CD} 45^{\text {intermediate }} \mathrm{CD} 117^{+}$. Human CEC population was defined as $\mathrm{CD} 31^{+} \mathrm{CD} 45^{-} \mathrm{CD} 146^{+}$and $\mathrm{CEP}$ population was defined as $\mathrm{CD} 31^{+} \mathrm{CD} 45^{\text {intermediate }} \mathrm{CD} 133^{+}$.

\section{Electron microscopy}

Sorted cells were fixed in $0.1 \mathrm{M}$ sodium cacodylate ( $\mathrm{pH} 7.4$ ) containing $5 \mathrm{~mm}$ calcium chloride and $2.5 \%$ glutaraldehyde for $24 \mathrm{~h}$ at $4{ }^{\circ} \mathrm{C}$, then embedded in $1 \%$ low-melting agarose. Samples were fixed with $2 \%$ tannic acid in the same primary fixative, rinsed and post fixed with osmium-tetroxide at $1 \%$ for $1 \mathrm{~h}$. Samples were en-bloc-stained with $1 \%$ aqueous uranyl acetate for $18 \mathrm{~h}$ at $4{ }^{\circ} \mathrm{C}$, then serially dehydrated and embedded in epoxy resin polymerised at $60^{\circ} \mathrm{C}$ for $48 \mathrm{~h}$. Seventy nanometre sections were observed at $300 \mathrm{kV}$ on a Tecnai F30 (FEI, Eindhoven, NL, USA), electron micrographs $(2 \mathrm{k} \times 2 \mathrm{k})$ were acquired using a US1000 (Gatan, Pleasanton, CA, USA).

\section{Statistical analysis}

Continuous data are presented as means or medians, and differences between groups determined using Student's $t$-test or the Mann-Whitney $U$-test as appropriate. Correlation between continuous variables was determined by calculating Spearman's rho or Pearson's $r$ following log transformation. To determine the effect of platelet number on the risk of biochemical recurrence (postoperative PSA $>0.2 \mathrm{ng} \mathrm{ml}^{-1}$ confirmed by a second reading of the same value of higher, or a serially rising PSA below this level that was believed by the treating physician to represent disease recurrence and led to the institution of salvage therapy), KaplanMeier curves were generated and differences between quintile levels assessed using the logrank test. Patients without recurrence were censored at the date of their last PSA test. To determine the value of preoperative $\mathrm{CD} 31^{+} \mathrm{CD} 45^{+}$cell counts for predicting treatment response post radical prostatectomy, a multivariable logistic regression model was fitted, and odds ratios and 95\% confidence intervals calculated. All statistical tests were two-sided, with $P<0.05$ considered significant. Analyses were performed using SPSS V.18 (SPSS, IBM, Armonk, NY, USA) and GraphPad Prism 5 (GraphPad, La Jolla, CA, USA).

\section{Ethics}

All animal experiments were approved by our institutional Animal Research Ethics Committee. The collection of patient blood samples and access to patient medical records for the CEC projects was approved by the Epworth Human Research Ethics Committee.

\section{RESULTS}

To determine whether levels of CECs and endothelial cell progenitors reflected differences in malignant behaviour, we measured them initially in two s.c. tumour models using the highly aggressive LLC cell line and an in-house-derived androgenindependent LNCaP (AI-LNCaP) cell line. As expected, the LLC cell line produced rapidly growing tumours (Figure $1 \mathrm{~A}$ ), with a mean volume of $2.48 \pm 0.23 \mathrm{cc}$ on day 21 compared with a final 
A

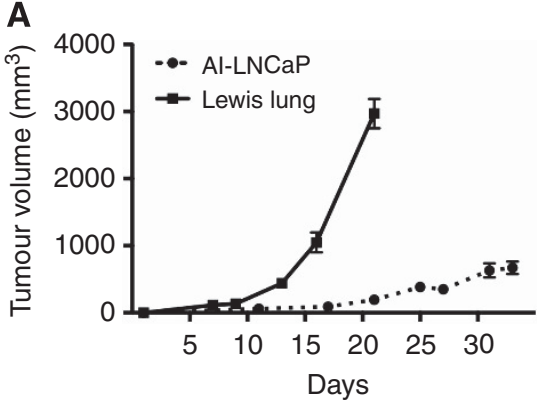

D

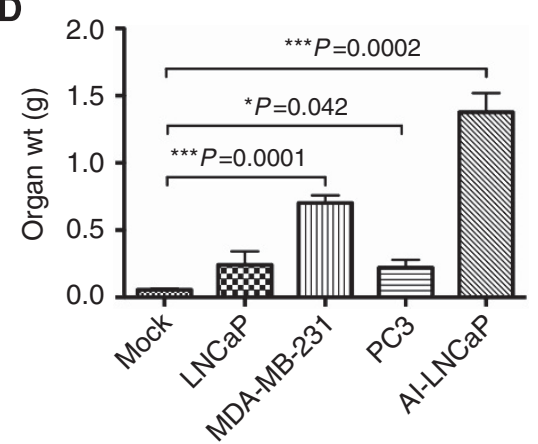

B
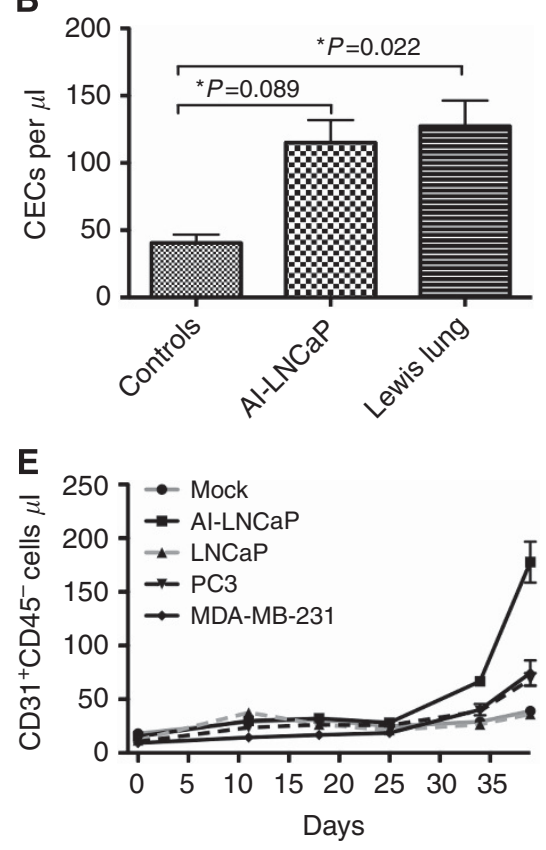

C
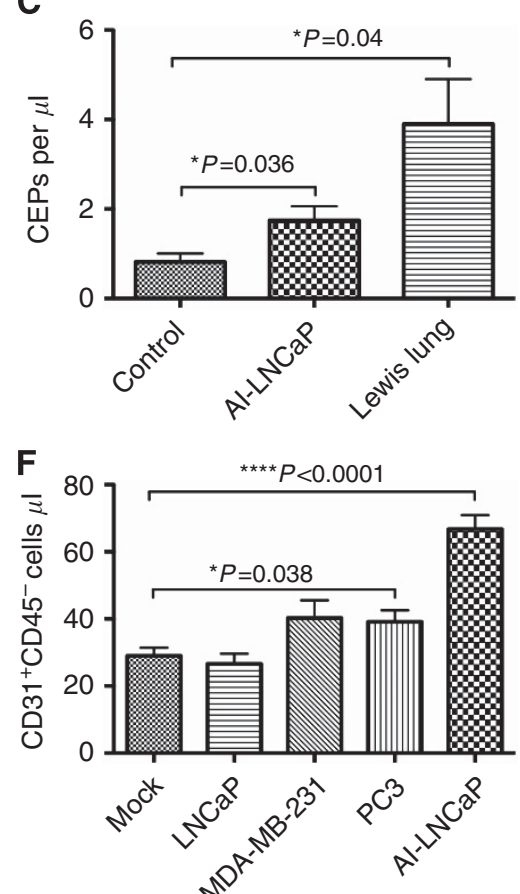

G

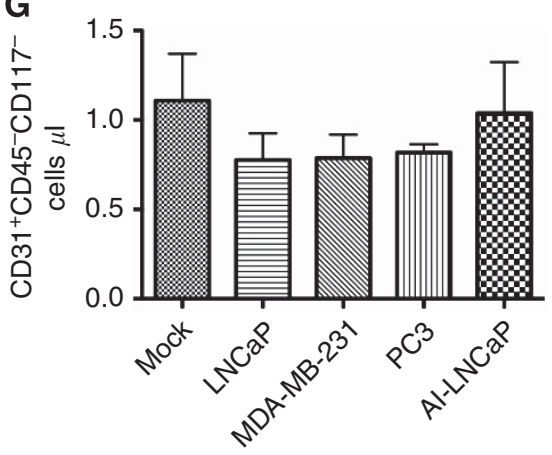

Figure I Levels of CEC $\left(C D 31{ }^{+} C D 45^{-}\right)$and CEP $\left(C D 31{ }^{+} C D 45^{-} C D I 17^{+}\right)$cells in preclinical models of prostate cancer. (A) Growth of s.c. tumour models (mean tumour volumes \pm s.e.m.) in SCID mice with either AI-LNCaP prostate or LLC tumour cells. (B) Mean CEC + s.e.m. levels at termination of experiment for s.c. tumour models and control injection groups. (C) Mean CEP + s.e.m. levels at termination of experiment for s.c. tumour models and control injection groups (D). Mean tumour weights + s.e.m. on day 39-40 in orthotopic xenograft models using the prostate cancer cell lines ATCC-LNCaP, PC3 and AI-LNCaP and the breast cancer cell line MDA-MB-23I. (E) Time course of mean CEC \pm s.e.m. levels in orthotopic xenograft models using the prostate cancer cell lines ATCC-LNCaP, PC3 and AI-LNCaP, as well as the breast cancer cell line MDA-MB-23I. (F) Mean CEC+ s.e.m. levels in orthotopic xenograft models, ATCC-LNCaP, PC3 and AI-LNCaP, and MDA-MB-23I tumours upon termination of experiment. (G) Mean CEP + s.e.m. levels in orthotopic xenograft models, ATCC-LNCaP, PC3 and AI-LNCaP, and MDA-MB-23I tumours upon termination of experiment. For all orthotopic models, six mice were used for each cancer cell line and three mice were used in mock surgical control groups.

volume (day 33) of $0.67 \pm 0.09 \mathrm{cc}$ observed with the AI-LNCaP cell line. Both CEC $\left(\mathrm{CD} 31^{+} \mathrm{CD}^{-} 5^{-}\right.$; control $40.57 \pm 6.14$; AI-LNCaP $115 \pm 16.86, P=0.0089$; Lewis lung $127.4 \pm 18.99, P=0.022)$ and $\mathrm{CEP} \quad\left(\mathrm{CD} 31^{+} \mathrm{CD}_{4}{ }^{-} \mathrm{CD}_{117}{ }^{+}\right.$; control $0.82 \pm 0.19 ; \quad$ AI-LNCaP $1.75 \pm 0.32, P=0.036$; Lewis lung $3.9 \pm 1.0, P=0.04$ ) levels were significantly elevated at the end of the experiment in both cell lines compared with the mock controls (Figure 1B and $\mathrm{C}$ ), although there was no significant difference between the two cell lines ( $P=0.64$ and $P=0.11$ for CECs and CEPs, respectively). To extend these findings we measured CEC and CEP levels in orthotopic xenograft models using the prostate cancer cell lines ATCCLNCaP, PC3 and AI-LNCaP, as well as the breast cancer cell line MDA-MB-231. The CEC and CEP levels were measured weekly and at the termination of the experiment on day 39-40, when tumourbearing organs were excised and weighed. The AI-LNCaP cell line produced the largest primary tumours (mean organ weight $1.38 \pm 0.14 \mathrm{~g}, P=0.0002$ ) compared with mock surgery controls
$(0.06 \pm 0.01 \mathrm{~g})$, followed by MDA-MB-231 $(0.7 \pm 0.06 \mathrm{~g}, P=0.001)$, ATCC-LNCaP $\quad(0.024 \pm 0.1 \mathrm{~g}, P=0.14)$ and PC3 $(0.22 \pm 0.06 \mathrm{~g}$, $P=0.042$ ) cell lines (Figure 1D). These differences in tumour growth were broadly reflected by changes in measured CEC levels, with significantly elevated levels observed earliest in mice harbouring AI-LNCaP tumours (day 33), followed by the PC3 and MDA-MB-231 (day 39) models (Figure 1E). At the end of the experiment CEC levels were also highest in the AI-LNCaP models $(66.77 \pm 4.23, P<0.0001)$ compared with the mock surgery controls $(29 \pm 2.45)$, with elevated levels also noted in the PC3 $(39.17 \pm 3.39$, $P=0.038)$ and MDA-MB-231 $(40.31 \pm 5.29, P=0.09)$ xenografts (Figure 1F). The CEC levels in the ATCC-LNCaP xenograft model, which in our hands produces small non-metastasising tumours, were not elevated compared with controls at any time point. Interestingly, despite a clear increase in CEP levels in s.c. models, no significant differences in CEP levels were observed at any time point with any cell line in the orthotopic xenografts (Figure 1G). 
A

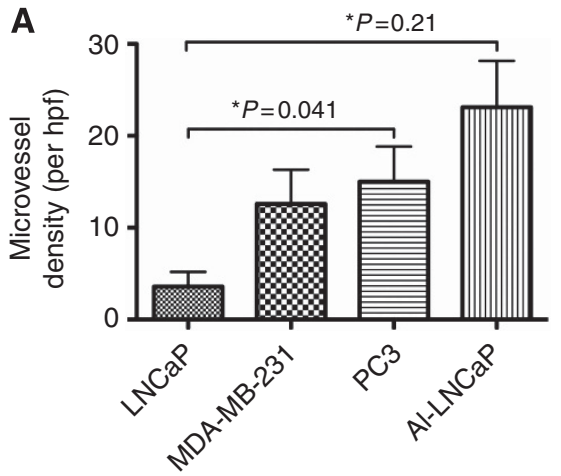

B

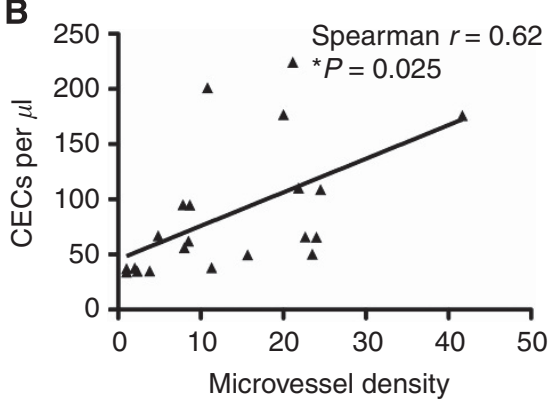

Figure 2 Circulating endothelial cell $\left(\mathrm{CD} 3 \mathrm{I}^{+} \mathrm{CD} 45^{-}\right)$levels correlate with MVD measures in orthotopic tumour models. (A) Mean MVD + s.e.m. $(n=6)$ from representative tumour sections isolated from indicated tumours at the end of experiment. (B) Correlation of MVD and mean CEC levels at termination of orthotopic models experiment $(n=6)$. (C) Representative $I H C$ images of orthotopic tumour sections stained with anti-CD3I antibody (brown) to quantify MVD. The relative tumour types are indicated in the panels.

As CECs are reported to be a surrogate marker of tumour neoangiogenesis, we next measured MVD, a pathological correlate of new blood vessel formation, in sections from orthotopic xenograft models (Figure $2 \mathrm{~A}$ and $\mathrm{C}$ ) and correlated them with CEC levels (Figure 2B). The increases in MVD observed with the more aggressive cell lines mirrored precisely the changes seen in CEC levels, with a significant positive correlation between the two variables (Pearson's $r=0.93637$ ).

To assess whether CEC and CEP levels are potentially useful biomarkers of treatment response in patients with clinically localised prostate cancer, we performed a prospective cohort study in men undergoing prostatectomy at our institution. Blood was collected for CEC and CEP measurement on the day of surgery in 164 men, the clinical and pathological characteristics of whom are summarised in Table 1 . To unambiguously identify the CEC population we added CD146 antigen positivity to the CD31 and CD45 measurements and to obviate specificity problems associated with some CD146 antibodies we chose an anti-CD146 clone previously determined as specific for this antigen and endothelial cells (Strijbos et al, 2007). We additionally measured the CD $31^{+}$ CD45 ${ }^{-}$cell population analogous to what we had measured in our preclinical models and which had shown remarkable correlation with tumour size, volume and MVD in the orthotopic models of prostate cancer.

We found that there was no significant difference in median $\mathrm{CD} 31^{+} \mathrm{CD} 45^{-}$cell levels between patient groups with increasing pathological stage (32.69, IQR 20.29-51.64 vs 28.58, IQR 22.16$47.67 ; P=0.86)$, the presence of extra-prostatic extension $(33.35$, IQR 20.84-52.03 vs 28.57, IQR 21.91-46.52; $P=0.068$ ) or increasing
Gleason score (Gleason 6 38.88, IQR 25.57-49.24 vs Gleason 7 28.57, IQR 20.84-50.49 vs Gleason 8-10 36.18, 23.89-48.85; $P=0.057$ ), nor was there any correlation with (log transformed) preoperative PSA (Spearman $r=0.047, P=0.55$ ) (Figure 3A-D). However, $\mathrm{CD} 31^{+} \mathrm{CD} 45^{-}$cell levels were significantly higher in men who experienced treatment failure within the first year, compared with those who did not (30.96, IQR 20.50-48.81 vs 50.01, IQR 30.15-62.93; $P=0.014$ ) (Figure 3E). We then analysed levels of the strict $\mathrm{CEC}$ population, $\mathrm{CD} 31^{+} \mathrm{CD} 45^{-} \mathrm{CD} 146^{+}$, but no significant difference was observed between the groups $(0$, IQR $0-0.04$ vs 0 , IQR $0-0.16 ; P=0.4$ ) (Figure $4 \mathrm{~A}$ ), nor was there any significant difference in median CEP $\left(\mathrm{CD} 31^{+}\right.$ $\mathrm{CD} 45^{\text {intermediate }} \mathrm{CD} 133^{+}$levels; 0.09, IQR $0-0.74$ vs 0.34 , IQR 0-1.32) (Figure 4B) noted.

To address whether $\mathrm{CD} 31^{+} \mathrm{CD} 45^{-}$cell levels are a potentially useful biomarker to guide treatment decision making in the preoperative setting, we performed a multivariable logistic regression analysis, including previously established predictors of treatment failure including preoperative PSA, clinical stage and biopsy Gleason score. In our model (Table 2, Supplementary Table 1), $\mathrm{CD} 31^{+} \mathrm{CD} 45^{-}$cells were an independent predictor of treatment failure, with the risk of recurrence increasing by $43 \%$ for every 10 cells increase in $\mathrm{CD} 31^{+} \mathrm{CD} 45^{-}$cell levels.

To identify the $\mathrm{CD} 31^{+} \mathrm{CD} 45^{-}$cell population we sorted and stained using Wright's-Giemsa this population of cells and observed using light microscopy a highly homogenous cell population comprising cells of approximately $5 \mu \mathrm{m}$ in diameter, exhibiting centrally located dense granular structures with irregular amounts of cytoplasm (Figure 5A). Further analysis of 
Table I Clinical and pathological characteristics of the radical prostatectomy cohort of 164 patients for CEC and CEP analyses

\begin{tabular}{|c|c|}
\hline $\bar{n}$ & $164(100 \%)$ \\
\hline \multicolumn{2}{|l|}{ Clinical stage } \\
\hline $\mathrm{lb}$ & $2(1.2 \%)$ \\
\hline Ic & 115 (70.1\%) \\
\hline $2 \mathrm{a}$ & $10(6.1 \%)$ \\
\hline $2 b$ & $24(14.6 \%)$ \\
\hline $2 c$ & $4(2.4 \%)$ \\
\hline $3 a$ & $4(2.4 \%)$ \\
\hline $3 b$ & $2(1.2 \%)$ \\
\hline Incomplete & $3(1.8 \%)$ \\
\hline \multicolumn{2}{|l|}{ Biopsy grade } \\
\hline Gleason $\leqslant 6$ & $45(27.4 \%)$ \\
\hline Gleason 7 & $87(53 \%)$ \\
\hline Gleason 8-10 & $28(17.1 \%)$ \\
\hline Incomplete & $4(2.4 \%)$ \\
\hline \multicolumn{2}{|c|}{ Preoperative PSA $\left(n g \mathrm{ml}^{-1}\right)$} \\
\hline Median & 6.1 \\
\hline IQR & $4.3-8.95$ \\
\hline \multicolumn{2}{|l|}{ Pathological stage } \\
\hline 2 & $108(65.9 \%)$ \\
\hline 3 & $56(34.1 \%)$ \\
\hline \multicolumn{2}{|c|}{ Extracapsular extension } \\
\hline Present & $53(32.3 \%)$ \\
\hline Absent & $111(67.7 \%)$ \\
\hline \multicolumn{2}{|c|}{ Seminal vesicle invasion } \\
\hline Present & II (6.7\%) \\
\hline Absent & $153(93.3 \%)$ \\
\hline \multicolumn{2}{|c|}{ Prostatectomy gleason score } \\
\hline 6 & $13(7.9 \%)$ \\
\hline 7 & $135(82.3 \%)$ \\
\hline $8-10$ & $16(9.8 \%)$ \\
\hline \multicolumn{2}{|c|}{ Early biochemical recurrence $(n=149)$} \\
\hline Yes & $12(8.1 \%)$ \\
\hline No & $137(91.9 \%)$ \\
\hline
\end{tabular}

Abbreviations: $C E C=$ circulating endothelial cells; $C E P=$ circulating endothelial progenitor; $I Q R=$ interquartile range; PSA = prostate-specific antigen.

the sorted cell population using electron microscopic analysis revealed the sorted $\mathrm{CD} 31^{+} \mathrm{CD} 45^{-}$cells lacked distinctive nuclei and contain open canalicular systems (OCS), alpha granules, dense bodies and were of the order of $3-5 \mu \mathrm{m}$ in size, features completely consistent with large, immature platelets (Figure 5B). We then performed flow cytometry using the platelet-specific markers $\mathrm{CD} 41 \mathrm{a}$ and $\mathrm{CD} 42 \mathrm{~b}$ on the $\mathrm{CD} 31^{+} \mathrm{CD}^{-} 5^{-}$cell population. We observed positive expression of both platelet-specific markers on the $\mathrm{CD} 31^{+} \mathrm{CD}^{-} 5^{-}$cell population (Figure $5 \mathrm{C}$ and $\mathrm{D}$ ). To test our hypothesis that levels of a specific subpopulation of platelets, but not total platelet levels, are an independent predictor of treatment failure, we performed a retrospective analysis using total platelet counts of an independent set of 364 prostatectomy patients (clinical and pathological characteristics are summarised in Table 3) before surgery to investigate the discriminatory ability of total platelet counts between non-recurrers and cancer recurring cohorts. There was no difference in total platelet levels between the two groups nor was there any difference between groups upon Kaplan-Meier survival analysis based on platelet number quintiles (Figure 5E and F). This supports our findings that only a specific subpopulation of total platelets is an independent predictor for early biochemical recurrence.

\section{DISCUSSION}

Circulating endothelial cells, thought to arise from shedding of the endothelial cell lining of the tumour vasculature as well as progenitor cells mobilised from the bone marrow compartment, have been proposed as surrogate biomarkers of tumour angiogenesis and hence might be useful as predictors of treatment response in early-stage prostate cancer as well as permitting the more accurate staging of patients for curative treatment interventions.

Although CECs and CEPs show promise as biomarkers of disease status, no consensus has emerged regarding surface markers that unambiguously identify these cells (Mancuso and Bertolini, 2010). A number of antigens have been utilised to identify CECs and CEPs, including CD31, CD34, CD105, CD146 and CD202B. Of these, CD146 would appear to be the most specific as an endothelial marker, with its expression limited to endothelial cells and a fraction of activated T cells (Bardin et al, 1996a, b; Blann et al, 2005; Elshal et al, 2005). However, doubts have been raised as to whether the purported cellular levels of CECs might be contaminated with levels of other haematogenous cells, in particular large platelets (Strijbos et al, 2007, 2008; Starlinger et al, 2011).

To identify human CECs and CEPs we utilised the most commonly employed technique of flow cytometry of fresh blood samples defining CECs as absence of the haematopoietic marker CD45 and presence of the endothelial markers CD31 and CD146. The CEPs were additionally identified by the expression of CD133.

Our preclinical results indicated a very strong correlation with levels of a $\mathrm{CD} 31^{+} \mathrm{CD} 45^{-}$circulating cell population and tumour size and volume in orthotopic xenograft models of prostate cancer. Interestingly, the increase in circulating $\mathrm{CD} 31^{+} \mathrm{CD} 45^{-}$numbers appeared to be a late event in tumour formation typically occurring around day 30 post tumour inoculation (Figure 1), excepting the very aggressive Lewis lung carcinoma cells, possibly indicative of the peak period of tumour vascularisation. However, no such correlation was observed with the CEP population, identified as $\mathrm{CD} 31^{+} \mathrm{CD} 45^{-} \mathrm{CD} 117^{+}$. The $\mathrm{CD} 31^{+} \mathrm{CD} 45^{-}$immunotype does not represent a strict population of CECs (Mancuso et al, 2009; Mancuso and Bertolini, 2010) but very likely includes a broader population of haematogenous cell types, including platelets (Strijbos et al, 2007), hence we utilised an additional endothelial-specific marker, $\mathrm{CD} 146^{+}$in our prospective human study to unambiguously identify the CEC population from other cell types. In the disease setting we selected, localised prostate cancer before surgical intervention, we found no utility in measuring either CEC or CEP levels either as correlates with existing clinico-pathological parameters or as predictive markers of early treatment failure. In contrast, intriguingly, we found that levels of the $\mathrm{CD} 31^{+} \mathrm{CD} 45^{-}$cell population acted as independent predictors of early treatment failure upon multivariable logistic regression models and that this cell population when sorted and identified comprised an essentially homogenous population of large immature platelets, representing $<0.1 \%$ of total circulating platelets. These results raise the intriguing possibility that these cells may serve as surrogate markers of micrometastatic disease in the localised prostate cancer setting before treatment intervention, as it is very likely that the cohort of early cancer recurrers were in affected patients whose cancers had already disseminated and seeded before surgery.

There is considerable experimental evidence that platelets contribute intimately to tumour metastasis. A number of platelet-expressed proteins have been demonstrated to be critical for tumour metastasis in experimental animal models with in particular LPA and beta-3 integrins shown to be necessary to support bone metastasis (Bakewell et al, 2003; Boucharaba et al, 2004). Platelets are also intimately involved with the processes driving tumour angiogenesis, through the release of many 

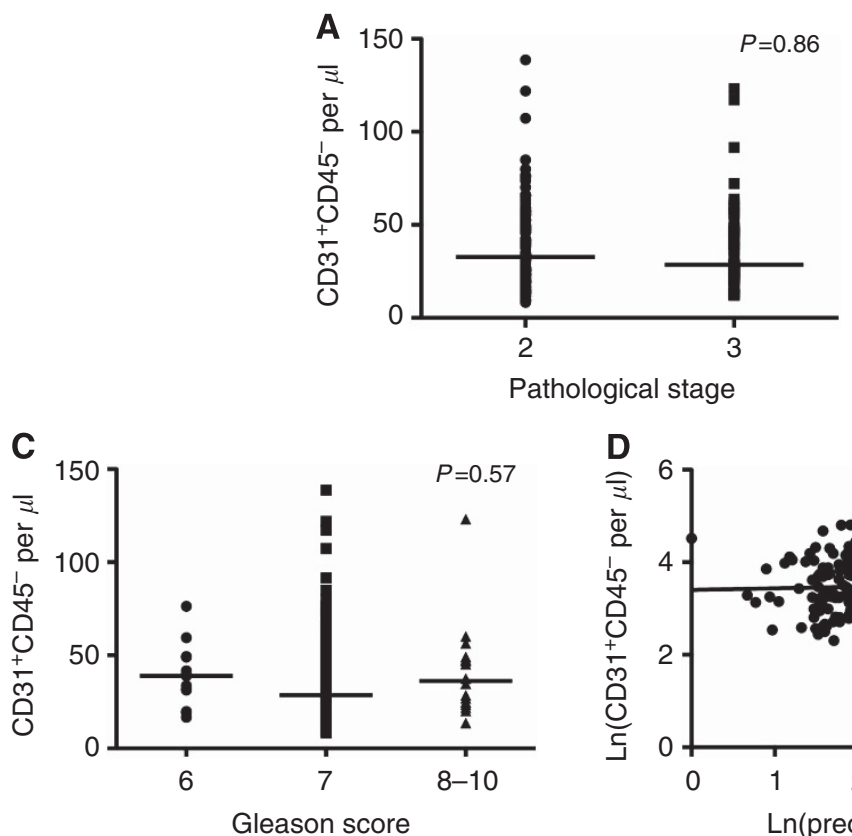

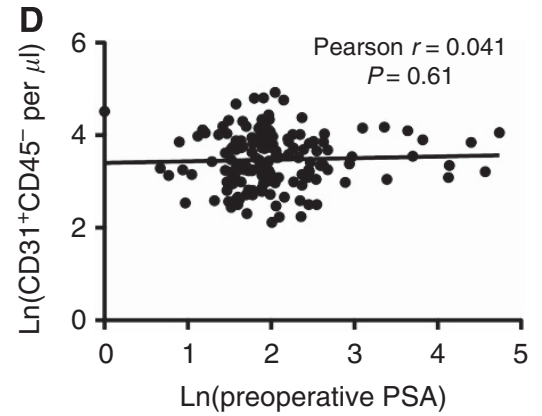

Figure 3 Comparison of median $\mathrm{CD} 3 \mathrm{I}^{+} \mathrm{CD} 45^{-}$cell levels and common clinico-pathological variables. (A) Median $\mathrm{CD} 3 \mathrm{I}^{+} \mathrm{CD} 45^{-}$cell levels in patient groups with increasing pathological stage. (B) Median $\mathrm{CD} 3 \mathrm{I}^{+} \mathrm{CD} 45^{-}$cell levels in patient groups with the presence of extra-prostatic extension. (C) Median $\mathrm{CD} 3 \mathrm{I}^{+} \mathrm{CD} 45^{-}$cell levels in patient groups with increasing Gleason score. (D) Correlation of median $\mathrm{CD} 3 \mathrm{I}^{+} \mathrm{CD} 45^{-}$cell levels with (log transformed) preoperative PSA. (E) Comparison of median CD31 ${ }^{+} \mathrm{CD} 45^{-}$cell levels in patient groups with early biochemical recurrence vs tumourfree patients.
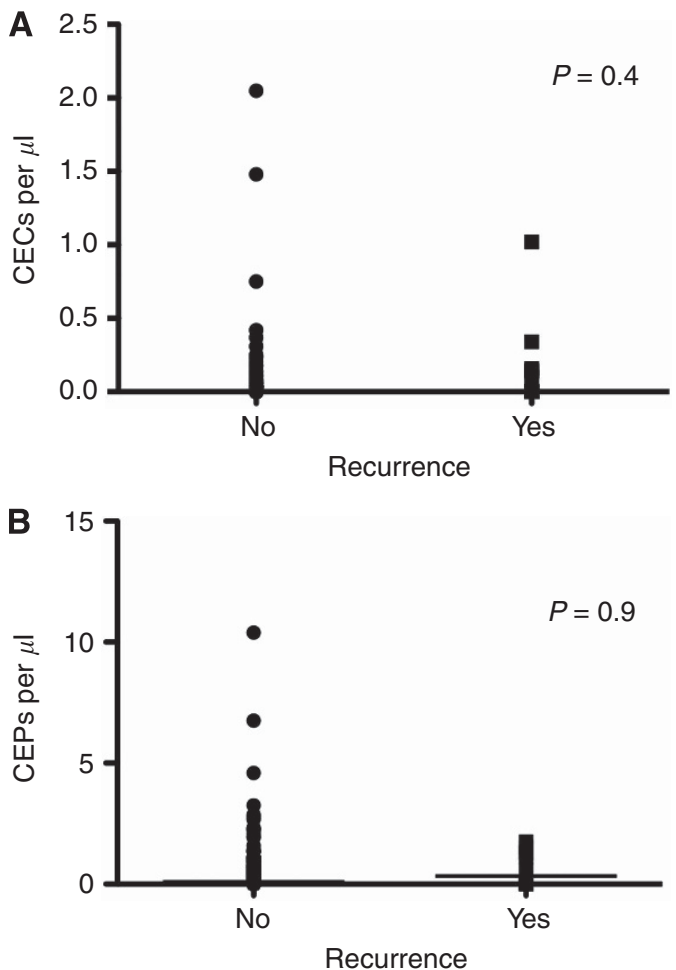

Figure 4 Comparison of median strict CEC and CEP cell levels and early biochemical recurrence. $(\mathbf{A})$ Median CEC $\left(\mathrm{CD} 3 \mathrm{I}^{+} \mathrm{CD} 45^{-} \mathrm{CDI} 46^{+}\right)$cell levels in patient groups with early biochemical recurrence vs tumour-free patients. (B) Median CEP $\left(\mathrm{CD} 31^{+} \mathrm{CD} 45^{\text {intermediate }} \mathrm{CD} / 33^{+}\right.$) cell levels in patient groups with early biochemical recurrence vs tumour-free patients.
Table 2 Multivariable logistic regression analysis including previously established predictors of treatment failure including preoperative PSA, clinical stage and biopsy Gleason score

\begin{tabular}{|c|c|c|c|}
\hline & ORs & $95 \%$ Cls & $P$ \\
\hline Clinical stage & 0.95 & $0.25-3.54$ & 0.94 \\
\hline Biopsy Gleason score & 2.69 & $0.66-11.04$ & 0.17 \\
\hline PSA $\left(10 \mathrm{ngml}^{-1}\right)$ & 2.11 & $|.3|-3.4 \mid$ & 0.002 \\
\hline $\mathrm{CD} 3 \mathrm{l}^{+} \mathrm{CD}_{45}^{-}(\mathrm{I} 0$ cells per microl $)$ & 1.43 & $1.1-1.87$ & 0.01 \\
\hline
\end{tabular}

Abbreviations: $\mathrm{Cl}=$ confidence interval; $\mathrm{OR}=$ odds ratio; $\mathrm{PSA}=$ prostate-specific antigen.

proangiogenic factors (Coppinger et al, 2004; Smyth et al, 2009) from activated platelets in the tumour microenvironment and enhanced levels of activated platelets have been reported in a variety of tumour types including prostate cancer (Sierko and Wojtukiewicz, 2007). Platelets also appear to have a vital role in supporting circulating tumour cell survival and eventual extravasation in the marginal environment of the bloodstream. Depletion of platelets inhibits metastasis (Gasic et al, 1968; Camerer et al, 2004), whereas platelet reconstitution restores experimental metastasis (Karpatkin et al, 1988). Nuclear factor erythroid-derived 2 (NFE2) knockout mice are devoid of circulating platelets and these mice are essentially refractory to experimental metastasis (Camerer et al, 2004). Additional evidence linking the key platelet proteins PAR4 and fibrinogen from knockout mice models have unambiguously demonstrated that activated platelets have an essential role in haematogenous spreading of tumours (Camerer et al, 2004). Given that platelets have been reported to adhere to circulating tumour cells, where they can protect the CTCs from NK cell induced lysis (Nieswandt et al, 1999), it is possible that we are measuring heterocellular 
A

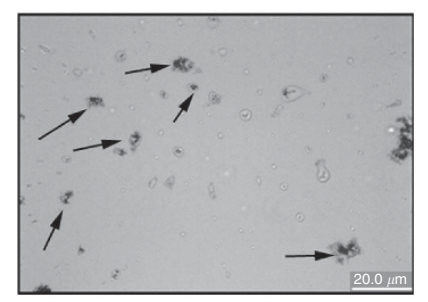

B

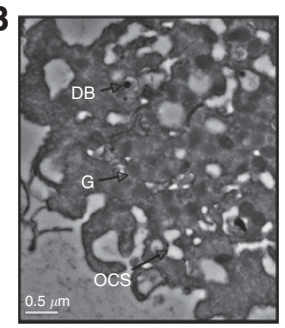

C

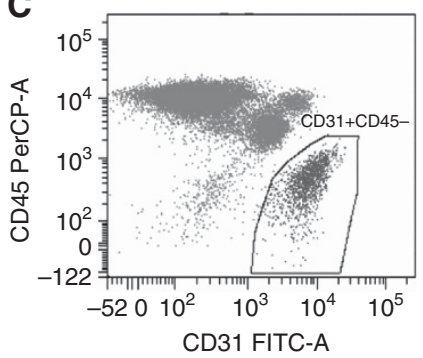

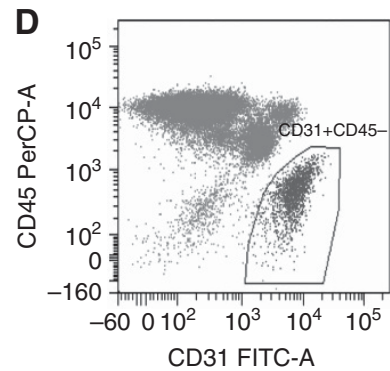
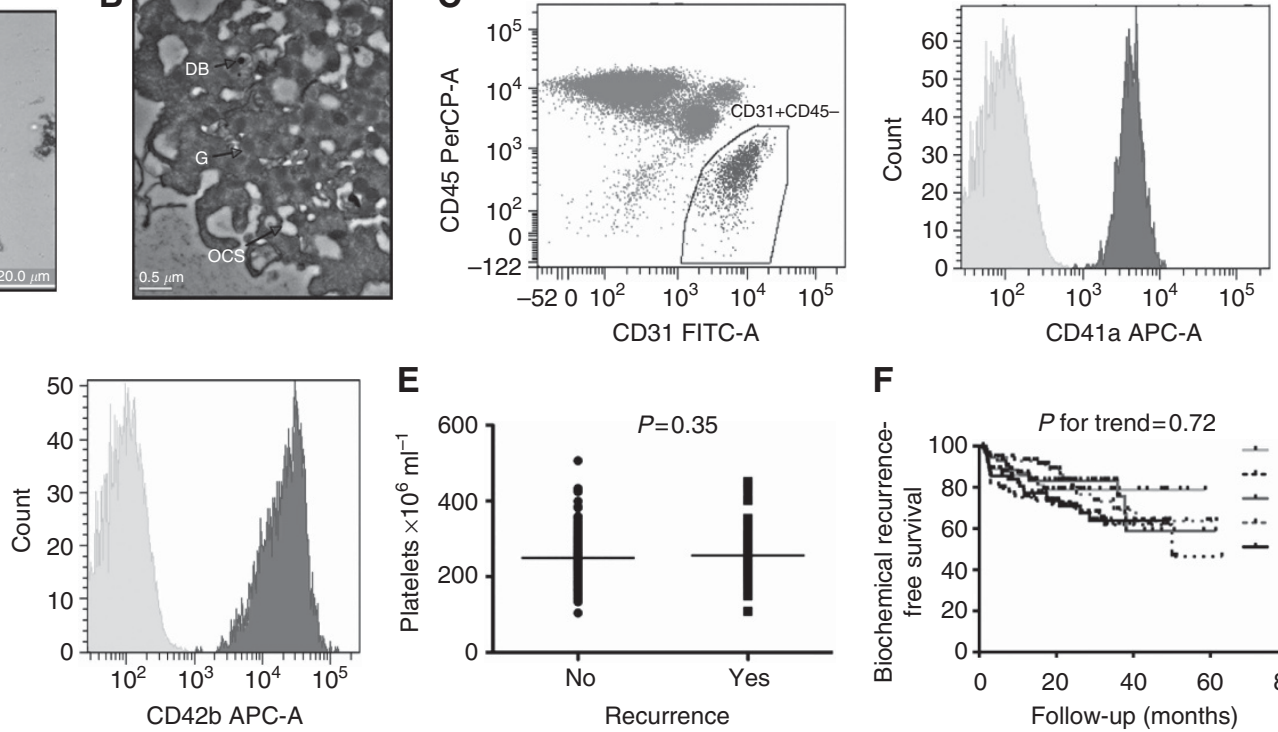

$\mathbf{F}$

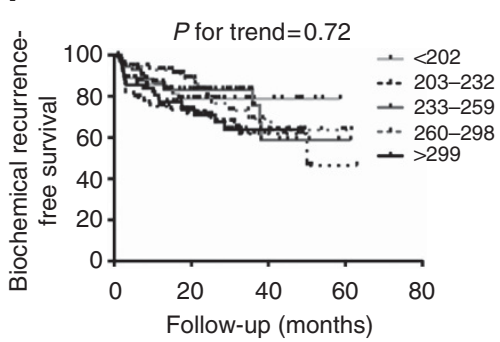

Figure 5 Characterisation of the FACS-sorted CD31 ${ }^{+} \mathrm{CD} 45^{-}$cells. (A) Wright's-Giemsa staining and light microscopy analysis of irregular shaped and dense granular structures (see arrows) comprising cells of approximately $5 \mu \mathrm{m}$ in diameter. (B) Electron microscopic analysis revealing cells lacking distinctive nuclei and contain OCS, alpha granules $(\mathrm{G})$ and dense bodies (DB) and were of the order of 3-5 $\mu \mathrm{m}$ in size. (C) Flow cytometry analysis showing $\mathrm{CD} 3 \mathrm{I}^{+} \mathrm{CD}_{4}{ }^{-}$cells have positive expression for two platelet-specific markers, (C) CD4Ia and (D) CD42b (light grey histograms indicate fluorescence patterns of unstained cells). (E) Comparison of levels of total platelets in the peripheral circulation of a large independent cohort of prostatectomy patients $(n=364)$ between non-recurrers and cancer-recurring cohorts. $(\mathbf{F})$ Kaplan-Meier survival analysis based on total peripheral circulation platelet number quintiles.

Table 3 Clinical and pathological characteristics of the radical prostatectomy cohort of 364 patients for total platelets analysis

\begin{tabular}{lc}
\hline$n$ & 364 \\
Age (years) & \\
Median & 61.8 \\
IQR & $57.4-65.8$ \\
PSA $\left(n g \mathrm{ml}^{-1}\right)$ & \\
Median & \\
IQR & 6.6 \\
& $5.1-8.7$ \\
Pathological stage & \\
PT2a & \\
PT2b & $2(1.2 \%)$ \\
PT2c & $115(70.1 \%)$ \\
PT3a & $10(6.1 \%)$ \\
PT3b & $24(14.6 \%)$ \\
3a & $4(2.4 \%)$ \\
& $4(2.4 \%)$ \\
Gleason score & \\
5 & \\
6 & $2(1.2 \%)$ \\
7 & $3(1.8 \%)$ \\
8 & $45(27.4 \%)$ \\
9 & $87(53 \%)$ \\
Total tumour volume (cc) & $28(17.1 \%)$ \\
Median & \\
IQR & \\
Platelets $\left(\times 10^{9}\right.$ per I) & 2.3 \\
Median & $1.1-4.6$ \\
IQR & \\
\hline
\end{tabular}

Abbreviations: $\mathrm{IQR}=$ interquartile range; $\mathrm{PSA}=$ prostate-specific antigen.

aggregates of platelets within the $\mathrm{CD} 31^{+} \mathrm{CD} 45^{-}$cell population via flow cytometry and this is a point warranting future analysis.

Platelets are highly labile cells derived from the structural disintegration of bone marrow megakaryocytes. Platelets can be activated typically by adhesion to subendothelial layers of the vasculature or via distinct stimuli such as arachidonate, ADP, thrombus or prostanoids. Upon such stimulation platelets undergo morphological change to expose functional surface receptors aggregate and release the content of their cytosolic granules.

Very little is known concerning whether there might exist specific subtypes of platelets; however, a specific subfraction of large platelets has been identified as being more haemostatically active raising much interest in the haematological sphere (Rinder et al, 1998).Immature platelets are relatively rich in megakaryocyte RNA and are also enlarged compared with more mature platelets. Recent measures of both the absolute numbers and fraction of these immature platelets suggest their clinical utility in paediatric blood disorders (Strauss et al, 2011).

Our identification of an increase in a specific subset of these platelets in patients with micrometastatic disease raises the intriguing possibility of tumour-orchestrated mobilisation of these immature platelets from the bone marrow, where they might aid in tumour cell survival and extravasation through direct contact with disseminated tumour cells as postulated by very recent work, showing that platelet adherence to circulating tumour cells provokes epithelial mesenchymal-like transition in the epithelial cells and ultimately invasive and aggressive phenotypes in experimental metastasis models (Labelle et al, 2011). These results strongly imply that secreted factors released from the distinct platelet reticular and granular system could directly enhance disseminated tumour cell survival extravasation and distant proliferation in micrometastatic niches.

In this regard it is of great interest that distinct subtypes of granules and OCS have very recently been identified using EM tomography and 3D reconstruction (van Nispen tot Pannerden et $a l$, 2010) of resting platelets, suggesting that previously unknown multiple distinct subclasses of platelets may exist.

It cannot be inferred from our results that CECs or CEPs do not have a role in tumour prognostication or as treatment response markers. Numerous positive studies attest to the potential of this biomarker, particularly as a treatment response marker in the advanced cancer setting following systemic drug treatment (Dome 
et al, 2006; Mancuso et al, 2006; Goon et al, 2009; Bertolini et al, 2011). However, it is interesting to speculate to what degree levels of CECs reported in studies may include other cell types other than 'pure' CECs. Our study was specifically designed to analyse the predictive potential of circulating cells as biomarkers of subclinical, micrometastatic disease in the early prostate cancer setting for which we have surprisingly discovered that a specific subset of circulating platelets namely, large immature platelets are markedly elevated in this setting. Given the very recent findings of a distinctive role for platelets in tumour cell dissemination and extravasation (Gay and FeldingHabermann, 2011), these results raise the possibility that these large immature platelets may not only serve as biomarkers of disease status but may be intimately involved in the prostate cancer metastatic

\section{REFERENCES}

Bakewell SJ, Nestor P, Prasad S, Tomasson MH, Dowland N, Mehrotra M, Scarborough R, Kanter J, Abe K, Phillips D, Weilbaecher KN (2003) Platelet and osteoclast beta3 integrins are critical for bone metastasis. Proc Natl Acad Sci USA 100(24): 14205-14210

Bardin N, Frances V, Lesaule G, Horschowski N, George F, Sampol J (1996a) Identification of the S-Endo 1 endothelial-associated antigen. Biochem Biophys Res Commun 218(1): 210-216

Bardin N, George F, Mutin M, Brisson C, Horschowski N, Frances V, Lesaule G, Sampol J (1996b) S-Endo 1, a pan-endothelial monoclonal antibody recognizing a novel human endothelial antigen. Tissue Antigen 48(5): 531-539

Beerepoot LV, Mehra N, Linschoten F, Jorna AS, Lisman T, Verheul HM, Voest EE (2004) Circulating endothelial cells in cancer patients do not express tissue factor. Cancer Lett 213(2): 241-248

Bertolini F, Mancuso P, Shaked Y (2011) Circulating endothelial cells as biomarkers for patients receiving bevacizumab. Lancet Oncol 12(3): $217-218$

Blann AD, Woywodt A, Bertolini F, Bull TM, Buyon JP, Clancy RM, Haubitz M, Hebbel RP, Lip GY, Mancuso P, Sampol J, Solovey A, Dignat-George F (2005) Circulating endothelial cells. Biomarker of vascular disease. Thromb Haemost 93(2): 228-235

Boucharaba A, Serre CM, Gres S, Saulnier-Blache JS, Bordet JC, Guglielmi J, Clezardin P, Peyruchaud O (2004) Platelet-derived lysophosphatidic acid supports the progression of osteolytic bone metastases in breast cancer. J Clin Invest 114(12): 1714-1725

Breton-Gorius J, Vainchenker W (1986) Expression of platelet proteins during the in vitro and in vivo differentiation of megakaryocytes and morphological aspects of their maturation. Semin Hematol 23(1): 43-67

Calleri A, Bono A, Bagnardi V, Quarna J, Mancuso P, Rabascio C, Dellapasqua S, Campagnoli E, Shaked Y, Goldhirsch A, Colleoni M, Bertolini F (2009) Predictive potential of angiogenic growth factors and circulating endothelial cells in breast cancer patients receiving metronomic chemotherapy plus bevacizumab. Clin Cancer Res 15(24): 7652-7657

Camerer E, Qazi AA, Duong DN, Cornelissen I, Advincula R, Coughlin SR (2004) Platelets, protease-activated receptors, and fibrinogen in hematogenous metastasis. Blood 104(2): 397-401

Coppinger JA, Cagney G, Toomey S, Kislinger T, Belton O, McRedmond JP, Cahill DJ, Emili A, Fitzgerald DJ, Maguire PB (2004) Characterization of the proteins released from activated platelets leads to localization of novel platelet proteins in human atherosclerotic lesions. Blood 103(6): 2096-2104

Corcoran NM, Casey RG, Hong MK, Pedersen J, Connolly S, Peters J, Harewood L, Gleave ME, Costello AJ, Hovens CM, Goldenberg SL (2012) The ability of prostate-specific antigen (PSA) density to predict an upgrade in Gleason score between initial prostate biopsy and prostatectomy diminishes with increasing tumour grade due to reduced PSA secretion per unit tumour volume. BJU Int 110(1): 36-42

Corcoran NM, Hong MK, Casey RG, Hurtado-Coll A, Peters J, Harewood L, Goldenberg SL, Hovens CM, Costello AJ, Gleave ME (2011) Upgrade in Gleason score between prostate biopsies and pathology following radical prostatectomy significantly impacts upon the risk of biochemical recurrence. BJU Int 108(8 Part 2): E202-E210

De Palma M, Venneri MA, Roca C, Naldini L (2003) Targeting exogenous genes to tumor angiogenesis by transplantation of genetically modified hematopoietic stem cells. Nat Med 9(6): 789-795 process, potentially opening novel avenues of targeted antimetastatic therapies in the future.

\section{ACKNOWLEDGEMENTS}

This study was supported by Australian Prostate Cancer Research Centre, Department of Health and Ageing, Victorian Prostate Cancer Research Consortium. B Namdarian was a scholar of the Royal Australian College of Surgeons. M Fankhauser was a scholar of the Cybec Foundation.

Supplementary Information accompanies the paper on British Journal of Cancer website (http://www.nature.com/bjc)

Dellapasqua S, Bertolini F, Bagnardi V, Campagnoli E, Scarano E, Torrisi R, Shaked Y, Mancuso P, Goldhirsch A, Rocca A, Pietri E, Colleoni M (2008) Metronomic cyclophosphamide and capecitabine combined with bevacizumab in advanced breast cancer. J Clin Oncol 26(30): 4899-4905

Demirer T, Ilhan O, Arat M, Genc Y, Ozcan M, Dalva K, Celebi H, Beksac M, Akan H, Gurman G, Konuk N, Uysal A, Arslan O, Koc H (2001) CD41 + and $\mathrm{CD} 42+$ hematopoietic progenitor cells may predict platelet engraftment after allogeneic peripheral blood stem cell transplantation. J Clin Apher 16(2): 67-73

Dome B, Timar J, Dobos J, Meszaros L, Raso E, Paku S, Kenessey I, Ostoros G, Magyar M, Ladanyi A, Bogos K, Tovari J (2006) Identification and clinical significance of circulating endothelial progenitor cells in human non-small cell lung cancer. Cancer Res 66(14): 7341-7347

Drayer AL, Olthof SG, Vellenga E (2006) Mammalian target of rapamycin is required for thrombopoietin-induced proliferation of megakaryocyte progenitors. Stem Cells 24(1): 105-114

Duda DG, Cohen KS, di Tomaso E, Au P, Klein RJ, Scadden DT, Willett CG, Jain RK (2006) Differential CD146 expression on circulating versus tissue endothelial cells in rectal cancer patients: implications for circulating endothelial and progenitor cells as biomarkers for antiangiogenic therapy. J Clin Oncol 24(9): 1449-1453

Dwenger A, Rosenthal F, Machein M, Waller C, Spyridonidis A (2004) Transplanted bone marrow cells preferentially home to the vessels of in situ generated murine tumors rather than of normal organs. Stem Cells 22(1): 86-92

Elshal MF, Khan SS, Takahashi Y, Solomon MA, McCoy Jr JP (2005) CD146 (Mel-CAM), an adhesion marker of endothelial cells, is a novel marker of lymphocyte subset activation in normal peripheral blood. Blood 106(8): 2923-2924

Gasic GJ, Gasic TB, Stewart CC (1968) Antimetastatic effects associated with platelet reduction. Proc Natl Acad Sci USA 61(1): 46-52

Gay LJ, Felding-Habermann B (2011) Contribution of platelets to tumour metastasis. Nat Rev Cancer 11(2): 123-134

Goon PK, Lip GY, Stonelake PS, Blann AD (2009) Circulating endothelial cells and circulating progenitor cells in breast cancer: relationship to endothelial damage/dysfunction/apoptosis, clinicopathologic factors, and the Nottingham Prognostic Index. Neoplasia 11(8): 771-779

Gothert JR, Gustin SE, van Eekelen JA, Schmidt U, Hall MA, Jane SM, Green AR, Gottgens B, Izon DJ, Begley CG (2004) Genetically tagging endothelial cells in vivo: bone marrow-derived cells do not contribute to tumor endothelium. Blood 104(6): 1769-1777

Karpatkin S, Pearlstein E, Ambrogio C, Coller BS (1988) Role of adhesive proteins in platelet tumor interaction in vitro and metastasis formation in vivo. I Clin Invest 81(4): 1012-1019

Koike T, Aoki S, Maruyama S, Narita M, Ishizuka T, Imanaka H, Adachi T, Maeda H, Shibata A (1987) Cell surface phenotyping of megakaryoblasts. Blood 69(3): 957-960

Labelle M, Begum S, Hynes RO (2011) Direct signaling between platelets and cancer cells induces an epithelial-mesenchymal-like transition and promotes metastasis. Cancer Cell 20(5): 576-590

Lyden D, Hattori K, Dias S, Costa C, Blaikie P, Butros L, Chadburn A, Heissig B, Marks W, Witte L, Wu Y, Hicklin D, Zhu Z, Hackett NR, Crystal RG, Moore MA, Hajjar KA, Manova K, Benezra R, Rafii S (2001) Impaired recruitment of bone-marrow-derived endothelial and 
hematopoietic precursor cells blocks tumor angiogenesis and growth. Nat Med 7(11): 1194-1201

Mancuso P, Antoniotti P, Quarna J, Calleri A, Rabascio C, Tacchetti C, Braidotti P, Wu HK, Zurita AJ, Saronni L, Cheng JB, Shalinsky DR, Heymach JV, Bertolini F (2009) Validation of a standardized method for enumerating circulating endothelial cells and progenitors: flow cytometry and molecular and ultrastructural analyses. Clin Cancer Res 15(1): 267-273

Mancuso P, Bertolini F (2010) Circulating endothelial cells as biomarkers in clinical oncology. Microvasc Res 79(3): 224-228

Mancuso P, Burlini A, Pruneri G, Goldhirsch A, Martinelli G, Bertolini F (2001) Resting and activated endothelial cells are increased in the peripheral blood of cancer patients. Blood 97(11): 3658-3661

Mancuso P, Colleoni M, Calleri A, Orlando L, Maisonneuve P, Pruneri G, Agliano A, Goldhirsch A, Shaked Y, Kerbel RS, Bertolini F (2006) Circulating endothelial-cell kinetics and viability predict survival in breast cancer patients receiving metronomic chemotherapy. Blood 108(2): 452-459

Monestiroli S, Mancuso P, Burlini A, Pruneri G, Dell'Agnola C, Gobbi A, Martinelli G, Bertolini F (2001) Kinetics and viability of circulating endothelial cells as surrogate angiogenesis marker in an animal model of human lymphoma. Cancer Res 61(11): 4341-4344

Nico B, Benagiano V, Mangieri D, Maruotti N, Vacca A, Ribatti D (2008) Evaluation of microvascular density in tumors: pro and contra. Histol Histopathol 23(5): 601-607

Nieswandt B, Hafner M, Echtenacher B, Mannel DN (1999) Lysis of tumor cells by natural killer cells in mice is impeded by platelets. Cancer Res 59(6): 1295-1300

Norden-Zfoni A, Desai J, Manola J, Beaudry P, Force J, Maki R, Folkman J, Bello C, Baum C, DePrimo SE, Shalinsky DR, Demetri GD, Heymach JV (2007) Blood-based biomarkers of SU11248 activity and clinical outcome in patients with metastatic imatinib-resistant gastrointestinal stromal tumor. Clin Cancer Res 13(9): 2643-2650

Peters BA, Diaz LA, Polyak K, Meszler L, Romans K, Guinan EC, Antin JH, Myerson D, Hamilton SR, Vogelstein B, Kinzler KW, Lengauer C (2005) Contribution of bone marrow-derived endothelial cells to human tumor vasculature. Nat Med 11(3): 261-262

Reyes M, Dudek A, Jahagirdar B, Koodie L, Marker PH, Verfaillie CM (2002) Origin of endothelial progenitors in human postnatal bone marrow. J Clin Invest 109(3): 337-346

Rinder HM, Tracey JB, Recht M, DeCastro L, Rinder CS, McHugh C, Smith BR (1998) Differences in platelet alpha-granule release between normals and immune thrombocytopenic patients and between young and old platelets. Thromb Haemost 80(3): 457-462

Ronzoni M, Manzoni M, Mariucci S, Loupakis F, Brugnatelli S, Bencardino K, Rovati B, Tinelli C, Falcone A, Villa E, Danova M (2010) Circulating endothelial cells and endothelial progenitors as predictive markers of clinical response to bevacizumab-based first-line treatment in advanced colorectal cancer patients. Ann Oncol 21(12): 2382-2389

Schneider DJ, Taatjes-Sommer HS (2009) Augmentation of megakaryocyte expression of FcgammaRIIa by interferon gamma. Arterioscler Thromb Vasc Biol 29(7): 1138-1143

Shaked Y, Bertolini F, Man S, Rogers MS, Cervi D, Foutz T, Rawn K, Voskas D, Dumont DJ, Ben-David Y, Lawler J, Henkin J, Huber J, Hicklin DJ, D'Amato RJ, Kerbel RS (2005a) Genetic heterogeneity of the vasculogenic phenotype parallels angiogenesis; Implications for cellular surrogate marker analysis of antiangiogenesis. Cancer Cell 7(1): $101-111$

Shaked Y, Emmenegger U, Man S, Cervi D, Bertolini F, Ben-David Y, Kerbel RS (2005b) Optimal biologic dose of metronomic chemotherapy regimens is associated with maximum antiangiogenic activity. Blood 106(9): 3058-3061

Sierko E, Wojtukiewicz MZ (2007) Inhibition of platelet function: does it offer a chance of better cancer progression control? Semin Thromb Hemost 33(7): 712-721

Smyth SS, McEver RP, Weyrich AS, Morrell CN, Hoffman MR, Arepally GM, French PA, Dauerman HL, Becker RC (2009) Platelet functions beyond hemostasis. J Thromb Haemost 7(11): 1759-1766

Soto AM, Lin TM, Sakabe K, Olea N, Damassa DA, Sonnenschein C (1995) Variants of the human prostate LNCaP cell line as tools to study discrete components of the androgen-mediated proliferative response. Oncol Res 7(10-11): 545-558

Starlinger P, Alidzanovic L, Schauer D, Brugger P, Sommerfeldt S, Kuehrer I, Schoppmann SF, Gnant M, Brostjan C (2011) Platelet-stored angiogenesis factors: clinical monitoring is prone to artifacts. Dis Markers 31(2): 55-65

Strauss G, Vollert C, von Stackelberg A, Weimann A, Gaedicke G, Schulze H (2011) Immature platelet count: a simple parameter for distinguishing thrombocytopenia in pediatric acute lymphocytic leukemia from immune thrombocytopenia. Pediatr Blood Cancer 57(4): 641-647

Strijbos MH, Gratama JW, Kraan J, Lamers CH, den Bakker MA, Sleijfer S (2008) Circulating endothelial cells in oncology: pitfalls and promises. $\mathrm{Br}$ J Cancer 98(11): 1731-1735

Strijbos MH, Kraan J, den Bakker MA, Lambrecht BN, Sleijfer S, Gratama JW (2007) Cells meeting our immunophenotypic criteria of endothelial cells are large platelets. Cytometry B Clin Cytom 72(2): 86-93

Tomer A, Harker LA, Burstein SA (1988) Flow cytometric analysis of normal human megakaryocytes. Blood 71(5): 1244-1252

Vainchenker W, Kieffer N (1988) Human megakaryocytopoiesis: in vitro regulation and characterization of megakaryocytic precursor cells by differentiation markers. Blood Rev 2(2): 102-107

van Nispen tot Pannerden H, de Haas F, Geerts W, Posthuma G, van Dijk S, Heijnen HF (2010) The platelet interior revisited: electron tomography reveals tubular alpha-granule subtypes. Blood 116(7): 1147-1156

This work is published under the standard license to publish agreement. After 12 months the work will become freely available and the license terms will switch to a Creative Commons Attribution-NonCommercial-Share Alike 3.0 Unported License. 